\title{
Utilization of L-Glutamic and 2-Oxoglutaric Acid as Sole Sources of Carbon by Escherichia coli
}

\author{
BY Y. S. HALPERN \\ Department of Bacteriology, Hebrew University-Hadassah Medical School, \\ Jerusalem, Israel, and \\ Department of Bacteriology and Immunology, Harvard Medical School, \\ Boston, Massachusetts, U.S.A. \\ AND H. E. UMBARGER* \\ Department of Bacteriology and Immunology, Harvard Medical School, \\ Boston, Massachusetts, U.S.A.
}

(Received 4 November 1960)

\begin{abstract}
SUMMARY
A wild-type strain of Escherichia coli (W) did not utilize glutamate or oxoglutarate as sole source of carbon for growth, but mutants able to grow on each of these compounds were isolated. The abilities to utilize glutamate and oxoglutarate did not necessarily accompany each other. The evidence presented supports the view that both kinds of mutant involve changes in a permeation mechanism. The mutation to growth on glutamate was always accompanied by appearance of sensitivity to inhibition by 2-methyl-DL-glutamic acid and by partial or even complete loss of glutamic acid decarboxylase. It is proposed that the permeation mechanism for glutamate also allows entry of 2-methylglutamate, a compound which prevents glutamine formation. The loss of glutamate decarboxylase remains unexplained.
\end{abstract}

\section{INTRODUCTION}

In the course of studies on the mechanism of utilization of ammonia by cultures of Escherichia coli it was noted that various strains differed in their ability to utilize L-glutamate and 2-oxoglutarate. Some of the strains used, including strain $\mathbf{W}$, were unable to grow on minimal media in which either of these compounds served as the carbon source (Halpern \& Umbarger, 1960). Later, mutants capable of utilizing glutamate or oxoglutarate were selected. The acquisition of the ability to grow on one of the two compounds appeared to be independent of the ability to grow on the other. It was of interest that all the wild-type $E$. coli strains which were unable to grow on glutamate possessed a highly active L-glutamic acid decarboxylase, while those that could utilize glutamate for growth showed no such activity. Similarly, mutants selected for ability to grow on glutamate lost most or all of their decarboxylase activity. Whereas no direct causal relationship between growth on glutamate and the absence of glutamic acid decarboxylase could be demonstrated, evidence has

* Present address: Biological Laboratory, Long Island Biological Association, Cold Spring Harbor, New York, U.S.A. 
been obtained which implicates specific permeation systems as prerequisites for the utilization of glutamate and oxoglutarate. These experiments are described in this paper. A preliminary report has been given elsewhere (Halpern \& Umbarger, 1959).

\section{METHODS}

Micro-organisms. The organisms used in this work were: Escherichia coli strains W, K-12, B and H; Aerobacter aerogenes strain 1033; a strain of Pseudomonas aeruginosa from the stock culture collection of the Department of Bacteriology and Immunology, Harvard Medical School.

Media. The minimal medium of Davis \& Mingioli (1950), with the omission of citrate, was used throughout. The various compounds used as carbon sources were prepared in separate solutions and added aseptically to the basal medium after autoclaving.

Selection of mutants. E. coli strain W was inoculated (about $5 \times 10^{7}$ organisms $/ \mathrm{ml}$.) into $100 \mathrm{ml}$. amounts of minimal medium with $0.5 \%(\mathrm{w} / \mathrm{v})$ L-glutamic or 2-oxoglutaric acid as the carbon source. The cultures were incubated at $37^{\circ}$ with shaking. Usually there was no detectable growth even after prolonged incubation (72 hr.). However, rapid increase in optical density ensued on the 5th day of incubation, the final concentrations of organisms equalling those obtained with succinate as carbon source. Such cultures were plated on eosin + methylene blue agar and single colonies were picked and tested for their ability to grow on the respective carbon source. Three glutamate-utilizing mutants were obtained on separate occasions by this method, and were designated $\mathrm{W} / \mathrm{Gl}_{1}, \mathrm{~W} / \mathrm{Gl}_{2}$ and $\mathrm{W} / \mathrm{Gl}_{3}$. One mutant utilizing oxoglutarate was also obtained and was designated W/KG. From strain $\mathrm{W} / \mathrm{Gl}_{\mathbf{1}}$ a secondary mutant was later selected for ability to utilize oxoglutarate in addition to glutamate; this mutant was designated $E$. coli W/Gl $/$ KG. Similarly, two glutamateutilizing mutants of $E$. coli $\mathbf{H}$ were obtained using this method, designated $\mathbf{H} / \mathrm{Gl}_{1}$ and $\mathbf{H} / \mathrm{Gl}_{2}$.

Growth experiments. For the determination of growth rates inocula from log-phase cultures were transferred to $20 \mathrm{ml}$. of appropriate medium in $250 \mathrm{ml}$. Erlenmeyer flasks with cuvette side arms. Such cultures were incubated at $37^{\circ}$ in a New Brunswick gyratory water-bath shaker. The changes in optical density were followed in a Klett-Summerson photoelectric colorimeter with a No. 42 filter.

Oxygen uptake measurements. Conventional manometric techniques were employed for the determination of oxygen uptake by cell suspensions.

Reduction of triphenyltetrazolium chloride. The capacity of bacterial suspensions, and bacteria disintegrated by sonic oscillation $(15 \mathrm{ml}$. of a cell suspension of $\mathrm{OD} \times 10=60$ at $550 \mathrm{~m} \mu$ in $\mathrm{M} / 15$ phosphate buffer, $\mathrm{pH} 7 \cdot 5$ was treated for $8 \mathrm{~min}$. in a Raytheon $10 \mathrm{KC}$ magnetostrictive sonic oscillator), to reduce triphenyltetrazolium chloride in the presence of glutamate was determined under both aerobic and anaerobic conditions. For the anaerobic experiments Thunberg tubes were used. The reaction was stopped by the addition of $0.1 \mathrm{ml} .4 \mathrm{~N}-\mathrm{HCl}$. The formazan formed was extracted with $2 \mathrm{ml}$. isobutanol and the colour intensity measured at $485 \mathrm{~m} \mu$ in a Coleman Junior spectrophotometer.

Preparation of cell-free extracts. Cell-free extracts used in the determinations of the enzymic activities studied were prepared by disintegration of bacterial suspen- 
sions $(\mathrm{OD} \times 10=60$ at $550 \mathrm{~m} \mu)$ in a Raytheon $10 \mathrm{KC}$ magnetostrictive sonic oscillator in the cold for $8 \mathrm{~min}$. The cell debris was removed by centrifugation in the cold $\left(4-6^{\circ}\right)$ for $15 \mathrm{~min}$. at $28,000 \mathrm{~g}$. The protein content of the supernatant liquid was determined by Mehl's biuret method (Mehl, 1945).

Assay of glutamic acid dehydrogenase. Glutamic acid dehydrogenase activity of cell-free extracts was determined by reduction of triphosphopyridine nucleotide (TPN) in the presence of L-glutamate, and its rate was followed at $340 \mathrm{~m} \mu$ in a Beckman model DU spectrophotometer. The reaction mixture contained: bacterial protein, $\mathbf{0 . 3} \mathrm{mg}$., different concentrations of L-glutamate (pH 8.7), TPN, $\mathbf{0 . 3} \mu$ mole, phosphate buffer ( $\mathrm{pH} 8.7$ ) $120 \mu$ mole, in a total volume of $3 \mathrm{ml}$. Increase in absorption at $340 \mathrm{~m} \mu$ was followed for $5 \mathrm{~min}$. at room temperature. Enzyme activity was calculated from the reaction rate for $1 \mathrm{~min}$. between the initial $\mathbf{3 0}$ and 90 sec. after addition of glutamate.

Assay of glutamine synthetase. Glutamine synthetase activity of cell-free extracts was determined in a system similar to that described by Fry (1955). The amounts of glutamine formed and glutamic acid utilized were estimated after paper chromatography, according to Giri, Radhakrishan \& Vaidyanathan (1952).

Assay of glutamic acid decarboxylase. Glutamic acid decarboxylase activity of extracts of cells grown in the presence of glutamate was determined manometrically or by paper chromatography as previously described (Halpern \& Grossowicz, 1956).

Determination of ${ }^{14} \mathrm{C}$-L-glutamate uptake by logarithmic phase cultures of Escherichia coli strains $W$ and $W / G l_{1}$. E. coli $W$ and $W / G_{1}$ were grown overnight (inoculum about $10^{7}$ organisms $/ \mathrm{ml}$.) in $20 \mathrm{ml}$. minimal medium containing a limiting amount of glucose $(0.05 \%, \mathrm{w} / \mathrm{v})$. Logarithmic growth was immediately resumed upon addition of $0.3 \%(\mathrm{w} / \mathrm{v})$ glucose. When the cultures reached a turbidity of $0.36($ at $550 \mathrm{~m} \mu)$, $1.5 \mathrm{ml}$. samples were withdrawn and incubated with various concentrations of ${ }^{14} \mathrm{C}$-uniformly labelled L-glutamate (The Radiochemical Centre, Amersham, Bucks), in the presence and in the absence of 2-methyl-DL-glutamic acid, $2 \cdot 79 \times 10^{-1} \mathrm{M}$, for $4 \mathrm{~min}$. at $37^{\circ}$ in a total volume of $2 \mathrm{ml}$. The reaction mixture was filtered in the cold through a bacterial membrane filter, $25 \mathrm{~mm}$. in diameter (Membranfilter, Göttingen, Gruppe:3) and rinsed with about $80 \mathrm{ml}$. ice-cold water. The filters were air-dried and their radioactivity measured in a Geiger-Muller counter ('Tracerlab, Inc.).

\section{RESULTS}

\section{Growth studies}

Following the observation that growth of Escherichia coli strain W on glutamate or on 2-oxoglutarate was possible only following selection of variants from a large population, experiments were performed to compare the growth rates of the variants with that of the wild strain on each of several carbon sources. Table 1 gives the results of such experiments. It was noted that with the acquisition of the ability to utilize glutamate or 2-oxoglutarate, there was little or no change in the growth rate on glucose or on another tricarboxylic acid cycle intermediate, succinate. In addition, it was apparent that the ability to grow on either glutamate or 2-oxoglutarate had no effect on the ability to grow on the other. Furthermore, for those strains which were able to grow on them, succinate, glutamate or 2-oxoglutarate were utilized for growth about equally effectively. Although the wild-type parent utilized glutamate as the source of nitrogen, it did so only poorly (column 6, Table 1). 
However, the strain which utilized glutamate as a source of carbon (strain $\mathrm{W} / \mathrm{Gl}_{\mathbf{1}}$ ) also used it better as a source of nitrogen, although it was able to utilize ammonia more effectively as a nitrogen source (column 2, Table 1).

Table 1. Growth of Escherichia coli strain $W$ and its mutants on different compounds serving as a sole source of carbon

The experiment was performed in minimal medium, to which $0.5 \%(\mathrm{w} / \mathrm{v})$ of the respective carbon source was added. The inocula were prepared from overnight cultures on succinate. The initial concentrations were about $2 \times 10^{8}$ organisms $/ \mathrm{ml}$. For other conditions, see Methods.

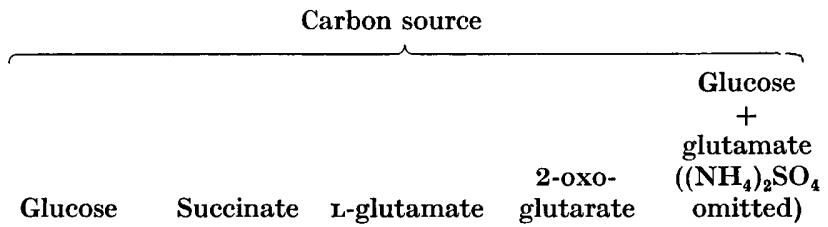

Strain

E. coli W

E. coli $\mathbf{W} / \mathbf{K G}$

E. coli $\mathrm{W} / \mathrm{Gl}_{1}$

E. coli $\mathrm{W} / \mathrm{Gl}_{1} / \mathrm{KG}$
Generation time (hr.)*

$\begin{array}{rrrrc}1.00 & 1.50 & >6 & >16 & 3.00 \\ 1.00 & 1.50 & >7 & 1.30 & - \\ 1.25 & 1.65 & 1.55 & >16 & 1.70 \\ - & - & 1.55 & 1.40 & -\end{array}$

* Time required for doubling of the optical density of the culture in the logarithmic phase of growth.

Table 2. Rates of oxygen uptake by suspensions of Escherichia coli $W$ and its mutants on various substrates

The bacteria were grown overnight on succinate as the carbon source, washed and resuspended in $0.05 \mathrm{~m}$ phosphate buffer $(\mathrm{pH} \mathrm{8.7)}$. Each Warburg vessel contained about $15 \mathrm{mg}$. equiv. dry weight organism, $\mathrm{MgCl}_{2}, 10 \mu \mathrm{mole}$, and phosphate buffer (pH 8.7) $50 \mu$ mole in the main compartment; $10 \mu$ mole of substrate in the side arm, and KOH $40 \%(\mathrm{w} / \mathrm{v}) 0.2 \mathrm{ml}$., in the centre well; total volume $1.5 \mathrm{ml}$; incubation at $30^{\circ}$.

\begin{tabular}{|c|c|c|c|}
\hline \multirow[b]{2}{*}{ Organisms } & \multicolumn{3}{|c|}{ Substrate } \\
\hline & $\begin{array}{l}\text { Succinate } \\
Q_{\mathrm{O}_{2}}{ }^{*}\end{array}$ & $\begin{array}{c}\text { L-Glutamate } \\
Q_{\mathrm{O}_{2}}{ }^{*}\end{array}$ & $\begin{array}{c}\text { 2-Oxoglutarate } \\
Q_{\mathrm{O}_{2}}{ }^{*}\end{array}$ \\
\hline E. $\operatorname{coli} \mathbf{W}$ & 540 & $49(93) \dagger$ & 90 \\
\hline E. $\operatorname{coli} \mathbf{W} / \mathbf{K G}$ & 540 & 8 & 264 \\
\hline E. coli $\mathrm{W} / \mathrm{Gl}_{1}$ & 522 & $402(18) \dagger$ & 100 \\
\hline E. coli $\mathrm{W} / \mathbf{G l}_{\mathbf{1}} / \mathbf{K G}$ & 468 & 336 & 234 \\
\hline
\end{tabular}

* The values obtained for endogenous respiration were subtracted from those obtained in the presence of substrate.

$\dagger$ Numbers in parentheses represent the amount of glutamic acid recovered at the end of the experiment, as \% of initial value.

\section{Rates of oxygen uptake}

Experiments were performed to determine the oxygen uptake of washed suspensions of the different strains. There was a very good correlation between respiratory activity towards the different carbon sources and the ability of a given strain to utilize these substances for growth (Table 2). When glutamate was the substrate, over $80 \%$ of it disappeared in the presence of strain $\mathrm{W} / \mathrm{Gl}_{1}$, whereas in the presence of the wild-type organism practically all of the added glutamate remained at the end of the experiment. 


\section{Glutamic acid dehydrogenase activity}

Since glutamic acid dehydrogenase might be involved in the early steps of glutamic and 2-oxoglutaric acid metabolism, the activity of this enzyme was investigated in extracts of Escherichia coli $\mathrm{W}$ and of the glutamate and oxoglutarate utilizing mutants. No significant differences between the activities of the various strains were detected.

\section{Reduction of triphenyltetrazolium chloride}

Different results were obtained when suspensions of Escherichia coli strains W and $\mathrm{W} / \mathrm{Gl}_{1}$ were tested for their ability to catalyse the transfer of electrons from glutamate to triphenyltetrazolium chloride. It can be seen that with intact organisms (Fig. 1) the apparent affinity of the wild strain for glutamate was much

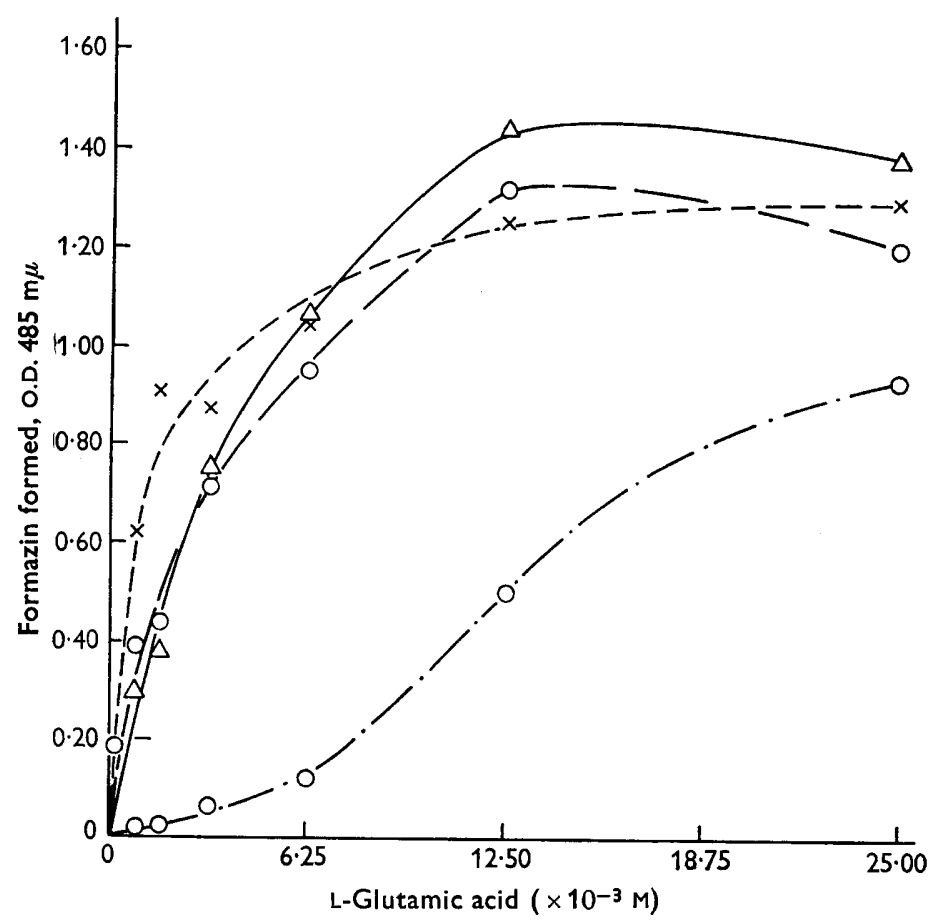

Fig. 1. Reduction of triphenyltetrazolium chloride by whole cell suspensions and by sonically disintegrated cells of $E$. coli $\mathrm{W}$ and $\mathrm{W} / \mathrm{Gl}_{\mathbf{1}}$ with glutamate as the electron donor. Overnight cultures of $E$. coli $W$ and $W / G_{1}$ on minimal medium, containing $1 \%(w / v)$ $\mathrm{Na}$-succinate and $0.5 \%(\mathrm{w} / \mathrm{v})$ L-glutamic acid, were washed and resuspended in $\mathrm{M} / \mathbf{1 5}$ phosphate buffer, $\mathrm{pH} 7 \cdot 5$. Both suspensions were adjusted to the same optical density $(\mathrm{OD} \times 10=60$ at $550 \mathrm{~m} \mu)$. Part of each suspension $(15 \mathrm{ml}$.) was disrupted in a Raytheon $10 \mathrm{KC}$ magnetostrictive sonic oscillator for $8 \mathrm{~min}$., and the remaining part was diluted with an equal volume of $\mathrm{m} / 15$ phosphate buffer, $\mathrm{pH} 7 \cdot 5$. The reaction mixtures contained: whole cell suspension ( $0.945 \mathrm{mg}$. dry weight of bacteria) or sonically disintegrated cells (4.413 mg. dry weight of bacteria), L-glutamic acid as indicated, triphenyltetrazolium chloride, $0.06 \%(\mathrm{w} / \mathrm{v})$, phosphate buffer $\mathrm{pH} 7 \cdot 5,467 \mu$ moles, in a total volume of $1.6 \mathrm{ml}$.; incubated aerobically at $37^{\circ}$ for $10 \mathrm{~min}$. The reaction was stopped by addition of $0.1 \mathrm{ml}$. $4 \mathrm{~N}-\mathrm{HCl}$; the formazan formed was extracted with isobutyl alcohol, $2 \mathrm{ml}$, and read at $485 \mathrm{~m} \mu$. - - - $\mathrm{O}_{-\cdot-}, \mathrm{W}$ whole cells; $-\mathrm{O}-\mathrm{W}$ broken cells; $-\times-, \mathbf{G l}_{1}$ whole cells; $-\triangle-, \mathbf{G l}_{1}$ broken cells. 
lower than that of the $\mathrm{Gl}_{1}$ mutant. In contrast, when sonically disrupted suspensions were used, the differences in the reaction rates of the two strains at either low or higher concentrations of glutamate were slight and perhaps not significant.

\section{Effect of 2-methyl-DL-glutamic acid}

Further evidence on the nature of the mutation to glutamate utilization was obtained by using a glutamate analogue, 2-methyl-DL-glutamate. This compound has been shown (Ayengar \& Roberts, 1952) to inhibit the growth of certain lactic acid bacteria, presumably by inhibiting the conversion of glutamate to glutamine. As shown in Table 3, when 2-methylglutamate was added to a glucose minimal medium, those Escherichia coli strains able to use glutamate as sole carbon source $\left(\mathrm{W} / \mathrm{Gl}_{1}\right.$, $\mathrm{W} / \mathrm{Gl}_{2}, \mathbf{B}, \mathbf{H} / \mathbf{G l}_{1}$ ) were inhibited by the analogue. Strains unable to grow on glutamate $(\mathrm{W}, \mathrm{K}-12, \mathrm{H})$ were resistant.

The correlation suggested by the results shown in Table 3 was further supported by isolating from the glutamate-utilizing mutant strain $\mathrm{W} / \mathrm{Gl}_{1}$ a variant, strain

Table 3. Inhibition of growth of different Escherichia coli strains by

$$
\text { 2-methyl-DL-glutamic acid }
$$

For conditions of growth see Methods.

In the presence of 2-methyl-DL-glutamic acid

\begin{tabular}{|c|c|c|c|c|c|}
\hline \multirow[b]{2}{*}{ Strain } & \multirow{2}{*}{$\begin{array}{l}\text { No additions } \\
\text { (control) } \\
\text { Klett reading }\end{array}$} & \multicolumn{2}{|c|}{$0 \cdot 15 \%(w / v)$} & \multicolumn{2}{|c|}{$0.50 \%(w / v)$} \\
\hline & & $\begin{array}{c}\text { Klett } \\
\text { reading }\end{array}$ & $\begin{array}{c}\text { Inhibition } \\
(\%)\end{array}$ & $\begin{array}{l}\text { Klett } \\
\text { reading }\end{array}$ & $\begin{array}{c}\text { Inhibition } \\
(\%)\end{array}$ \\
\hline E. $\operatorname{coli} \mathbf{W}$ & 375 & 313 & 16.5 & 290 & $22 \cdot 7$ \\
\hline E. coli $\mathbf{W} / \mathbf{G l}_{1}$ & 443 & Not tested & & 26 & $94 \cdot 1$ \\
\hline E. coli $\mathbf{W} / \mathbf{G l}_{2}$ & 242 & 31 & $87 \cdot 2$ & 5 & $97 \cdot 9$ \\
\hline E. coli $\mathrm{K}-12$ & 280 & 345 & 0 & Not tested & \\
\hline E. coli B & 325 & 23 & 92.9 & 10 & 96.9 \\
\hline E. coli $\mathbf{H}$ & 415 & 275 & $33 \cdot 7$ & 202 & $51 \cdot 3$ \\
\hline E. $\operatorname{coli} \mathbf{H} / \mathbf{G l}_{1}$ & 510 & 12 & $97 \cdot 6$ & 15 & $97 \cdot 1$ \\
\hline
\end{tabular}

Table 4. Uptake of ${ }^{14} \mathrm{C}-\mathrm{L}$-glutamate by Escherichia coli strains $W$ and $W / G l_{1}$ in the presence and in the absence of 2-methyl-DL-glutamic acid

The reaction mixture contained: logarithmic phase organisms equiv. $0.567 \mathrm{mg}$. dry wt. bacteria, in minimal medium containing $0.3 \%(\mathrm{w} / \mathrm{v})$ glucose, ${ }^{14} \mathrm{C}-\mathrm{L}$-glutamate (uniformly labelled, 107 c.p.m. $/ \mu$ mole) and 2-methyl-nL-glutamic acid as indicated, in a total volume of $2 \mathrm{ml}$; ; incubation in a water-bath with shaking (about 200 oscillations/min.) at $37^{\circ}$ for $4 \mathrm{~min}$. For other conditions see Methods.

\begin{tabular}{|c|c|c|c|c|c|c|}
\hline & & Upta & of ${ }^{14} \mathrm{C}-\mathrm{L}-\mathrm{g}$ & tamate & .m.) & \\
\hline & & E. coli W & & & E. $\operatorname{coli} \mathbf{W} / \mathbf{G l}$ & \\
\hline & 2-Methy & $\begin{array}{l}\text {-glutamate } \\
\text { led }\end{array}$ & & 2-Methy & $\begin{array}{l}\text { L-glutamate } \\
\text { ded }\end{array}$ & \\
\hline $\begin{array}{l}{ }^{14} \mathrm{C}-\mathrm{-L} \text {-glutamate } \\
\text { added (M) }\end{array}$ & None & $2.79 \times 10^{-1} M$ & $\begin{array}{c}\% \\
\text { Inhibition }\end{array}$ & None & $2.79 \times 10^{-1} \mathrm{M}$ & $\begin{array}{c}\% \\
\text { Inhibition }\end{array}$ \\
\hline $9.3 \times 10^{-6}$ & 287 & 230 & $19 \cdot 9$ & 455 & 225 & $50 \cdot 1$ \\
\hline $2.8 \times 10^{-5}$ & 631 & 523 & $17 \cdot 1$ & 1024 & 491 & $\mathbf{5 2 \cdot 0}$ \\
\hline $8.4 \times 10^{-5}$ & 1070 & 992 & $7 \cdot 3$ & 1703 & 1251 & $26 \cdot 5$ \\
\hline
\end{tabular}


$\mathrm{W} / \mathrm{Gl}_{1} / \mathbf{M G}$, selected for ability to grow in glucose minimal medium +2-methylglutamate. This variant was found to have lost its ability to grow on glutamate. Similarly, another derivative, strain $\mathrm{W} / \mathrm{GI}_{1}-8$, was selected by means of the penicillin selection method (Davis, 1948) for restoration of the original inability to grow on glutamate; this strain was found to have lost its sensitivity to 2-methylglutamate. In contrast, when the glutamine-synthesizing systems were tested in extracts it was observed that the activity in extracts of both Escherichia coli strains W and $\mathbf{W} / \mathbf{G l}_{1}$ was inhibited by the analogue (78-88\% inhibition by 0.011 M-2-methylglutamate).

Further evidence which stresses the relationship between the ability of the organism to utilize L-glutamate and the inhibitory effect of 2-methyl-DL-glutamate on its growth was obtained by uptake experiments described in Table 4. As shown in Table 4, uptake of ${ }^{14} \mathrm{C}$-labelled $\mathrm{L}$-glutamic acid by Escherichia coli $\mathrm{W} / \mathrm{Gl}_{1}$ was considerably higher than that by the W strain and was inhibited to the extent of $50 \%$ in the presence of the 2-methyl analogue. On the other hand, addition of 2-methylDL-glutamic acid caused an inhibition of L-glutamate uptake by strain $W$ of less than $20 \%$. The residual (uninhibited) uptake was virtually the same in both strains.

\section{Table 5. Comparison of L-glutamic acid decarboxylase activities of various mutants of Escherichia coli}

The reaction mixtures in Warburg flasks contained: bacterial extract equiv. 0.75 mg. protein, L-glutamic acid, $15 \mu$ mole; acetate buffer (pH 4.5) $90 \mu$ mole; pyridoxal phosphate, $150 \mu \mathrm{g}$; in a total volume of $1.5 \mathrm{ml}$. Incubation was at $30^{\circ}$. The extract in each case was prepared from organisms harvested in the logarithmic phase from a medium containing initially $1.0 \%(\mathrm{w} / \mathrm{v})$ glucose and $0.5 \%(\mathrm{w} / \mathrm{v}) \mathrm{L}$-glutamate.

\begin{tabular}{|c|c|c|c|c|}
\hline Strain & $\begin{array}{c}\text { Glutamate } \\
\text { as sole } \\
\text { carbon } \\
\text { source }\end{array}$ & $Q_{\mathrm{O}_{2}}$ & Strain & $\begin{array}{l}\text { Glutamate } \\
\text { as sole } \\
\text { carbon } \\
\text { source }\end{array}$ \\
\hline E. coli W & - & 592 & E. $\operatorname{coli} \mathbf{H} / \mathbf{G l}_{\mathbf{2}}$ & + \\
\hline E. coli $\mathrm{W} / \mathrm{Gl}_{1}$ & + & 20 & E. coli $\mathrm{K}-12$ & - \\
\hline E. $\operatorname{coli} \mathrm{W} / \mathrm{Gl}_{2}$ & + & 224 & E. coli $\mathbf{B}$ & + \\
\hline E. coli $\mathrm{W} / \mathrm{Gl}_{3}$ & + & 20 & A. aerogenes 1033 & + \\
\hline E. $\operatorname{coli} \mathbf{H}$ & - & 1467 & Ps. aeruginosa & + \\
\hline E. coli $\mathbf{H} / \mathrm{Gl}_{1}$ & + & 452 & & \\
\hline
\end{tabular}

\section{Glutamate decarboxylase activity in glutamate-utilizing strains}

The only enzymic difference noted between extracts of organisms unable to grow on glutamate and extracts of those able to utilize glutamate was in the decarboxylation of glutamate. Thus Escherichia coli strains W, K-12 and $\mathbf{H}$ exhibited strong glutamic acid decarboxylase activity, whereas variants of these strains which can grow on glutamate, showed either a partial or a complete loss of the decarboxylase. It was also found that the three wild-type organisms which were observed to utilize glutamate as a carbon source, $E$. coli strain B, Aerobacter aerogenes strain 1033 and the strain of Pseudomonas aeruginosa, exhibited no glutamic acid decarboxylase activity (Table 5). At present, the mechanism underlying this apparent correlation is not clear. The relationship, however, does not appear to be a direct one. For example, selection for loss of the ability to utilize glutamate or for resistance to 2-methylglutamate (such as strains $\mathrm{W} / \mathrm{Gl}_{1}-8$ and $\mathrm{W} / \mathrm{Gl}_{1} / \mathrm{MG}$ described above) did not select organisms which had gained the ability to decarboxylate glutamate. 


\section{DISCUSSION}

The difference between Escherichia coli $\mathrm{W}$ and its mutants, with respect to their ability to utilize glutamate and oxoglutarate for growth, might have been due either to changes in the respective metabolic pathways or to changes in the ability of the organisms to take up the substrates. Although glutamate oxidation by strains selected for growth on glutamate was much higher than that in strains unable to grow on glutamate, the glutamic dehydrogenase activities of the extracts prepared from the two kinds of strains were not significantly different. This difference must be accounted for, therefore, by a difference in the ease of entry of glutamate into the cells of the two strains. This hypothesis is directly supported by the observations on the difference in tetrazolium reduction as between whole organisms and extracts. Thus, at low concentrations of glutamate there was a distinct difference in the rates of tetrazolium reduction by intact organisms of the two strains. This difference could be essentially abolished by disrupting the organisms or by using higher concentrations of glutamate. The change in the glutamate-utilizing mutant could probably best be explained by an increased capacity to transport glutamate into the cell.

A difference between the penetration of glutamate into organisms of strain $\mathbf{W}$ and into organisms of strain $\mathrm{W} / \mathrm{Gl}_{1}$ could also explain the difference in the sensitivity of the two kinds of organism to 2-methylglutamate, a compound which inhibits glutamine formation by extracts of both strains. It would appear that the same mechanism which is responsible for the transport of glutamate into the cell also facilitates the penetration of the analogue.

Although it is not clear how the loss of decarboxylase activity is related to the utilization of glutamate, the two phenomena nevertheless seem to be connected. In every mutant examined the appearance of the ability to grow on glutamate was accompanied by a total or at least partial loss of glutamic decarboxylase activity. Even the relatively high decarboxylase activity of strain $\mathrm{H} / \mathrm{Gl}_{1}\left(Q_{\mathrm{Co}_{2}}=452\right)$ comprises only $30 \%$ of the activity of the parent $\mathbf{H}$ strain. The same argument holds also for the decarboxylase of strain $\mathrm{W} / \mathrm{Gl}_{2}$, which, although being as active as that of Escherichia coli K-12 unable to grow on glutamate, is nevertheless only one-third as active as that of its parent $W$ strain.

Finally, it may be pointed out that the data in Table 1 provide evidence that the mutation to growth on 2-oxoglutarate was also due to a change in a penetration mechanism. The present evidence for a similar system in Escherichia coli is less conclusive than in the case of glutamate. However, if it may be assumed that glutamate utilization proceeds via 2-oxoglutarate, it is clear that an organism which metabolizes glutamate at a rate sufficient for growth must also metabolize endogenous oxoglutarate at a rate sufficient for growth. Since such strains do not grow on exogenous oxoglutarate, their failure to do so must be attributed to the inability of this compound to enter the cell. It is of interest that Kogut \& Podoski (1953) presented evidence for the existence of an oxoglutarate permeation system in a Pseudomonas strain.

This work was supported by funds received from the United States Public Health Service Grants no. E1540 and no. 2021, and the Joint Research Fund Hebrew 
University-Hadassah Medical School, Jerusalem. This work was initiated during the tenure of a Fulbright Scholarship (1958-1959) by Y.S.H., who wishes to express his sincere appreciation to Dr B. D. Davis for his generous support that made this visit possible. A Lederle Medical Faculty Award was made to H.E.U. during the earlier part of this work.

\section{REFERENCES}

Ayengar, P. \& Roberts, E. (1952). Inhibition of utilization of glutamic acid by Lactobacillus arabinosus. Proc. Soc. exp. Biol., N.Y. 79, 476.

Davrs, B. D. (1948). The isolation of biochemically deficient mutants of bacteria by means of penicillin. Proc. nat. Acad. Sci., Wash. 35, 1.

Davis, B. D. \& Mingroli, E. S. (1950). Mutants of Escherichia coli requiring methionine or vitamin $B_{12}$. J. Bact. $60,17$.

Fry, B. A. (1955). Glutamine synthesis by Micrococcus pyogenes var. aureus. J. gen. Microbiol. 59, 579.

Giri, K. V., Radhakrishnan, A. N. \& Vaidyanathan, C. S. (1952). A simple paper chromatographic method for the study of transamination reactions. Nature, Lond. 170, 1025.

Halpern, Y. S. \& Grossowicz, N. (1956). Determination of L-glutamic acid by the use of L-glutamic acid decarboxylase from Mycobacterium phlei. Proc. Soc. exp. Biol., N.Y. 91, 370.

HaLPERN, Y. S. \& Umbarger, H. E. (1959). Glutamic decarboxylase-the limiting factor in the utilization of glutamate as a carbon source by Escherichia coli. Bact. Proc. p. 122.

Halpern, Y. S. \& Umbarger, H. E. (1960). Conversion of ammonia to amino groups in Escherichia coli. J. Bact. 80, 285.

Kogut, M. \& Podoski, E. P. (1953). Oxidative pathways in a fluorescent Pseudomonas. Biochem. J. 55, 800.

MenL, J. W. (1945). The biuret reaction of proteins in the presence of ethylene glycol. J. biol. Chem. 157, 173. 